\title{
International Order Flows: Explaining Equity and Exchange Rate Returns
}

\author{
Peter Dunne*
}

Queens University, Belfast

\author{
Harald $\mathrm{Hau}^{* *}$
}

INSEAD and CEPR

\author{
Michael Moore***
}

Queens University, Belfast

November 2005

\begin{abstract}
Macroeconomic models of equity and exchange rate returns perform poorly. The proportion of daily returns that these models explain is essentially zero. Instead of relying on macroeconomic determinants, we model equity price and exchange rate behavior based on a concept from microstructure - order flow. The international order flows are derived from belief changes of different investor groups in a two country setting. We obtain a structural relationship between equity returns, exchange rate returns and their relationship to home and foreign market order flow. To test the model we construct daily aggregate order flow data from all equity trades in the U.S. and France from 1999 to 2003. Almost 60 percent of the daily returns in the S\&P100 index is explained jointly by exchange rate returns and aggregate order flows.
\end{abstract}

Anantha Ranganathan provided outstanding research assistance. Thanks to Gauthier Lanot, Rich Lyons, Carol Osler, Helene Rey, and Dagfinn Rime for helpful discussions. We also benefitted from comments by seminar participants at Harvard University, UCLA, UC Berkeley, Brandeis University, University of Toulouse, University of Dortmund, Maynooth University and Queen's University Belfast. Particular gratitude to Kx Systems, Palo Alto, and their European partner, First Derivatives, for providing their database software Kdb.

${ }^{*}$ School of Management and Economics, Queens University, Belfast, BT7 1NN, Northern Ireland, United Kingdom. Telephone: (++44) 289097 3310. E-mail: p.g.dunne@qub.ac.uk. Web page: www.qub-efrg.com/staff/pdunne/

** Department of Finance, Boulevard de Constance, 77305 Fontainebleau Cedex, France. Telephone: (++33) 160724484. Fax: (33)-1 6074 5500. E-mail: harald.hau@insead.edu. Web page: http://faculty.insead.fr/hau/

${ }^{* * *}$ School of Management and Economics, Queens University, Belfast, BT7 1NN, Northern Ireland, United Kingdom. Telephone: (++44) 289097 3208. E-mail: m.moore@qub.ac.uk. Web page: www.qub-efrg.com/staff/mmoore/ 


\section{Introduction}

The aggregate stock market index and the exchange rate are known to have a very low correlation with any other measurable macroeconomic variable (Frankel and Rose (1995), Rogoff (2001)). This motivates us to examine a new financial market variable called order flow in its relationship to stock and exchange rate returns. Order flow is the net of buy minus sell initiated orders. ${ }^{1}$ In the foreign exchange market, daily exchange rate returns and daily order flow show a remarkably high correlation (Evans and Lyons (2002a, 2002b, 2002c)) and even permanent changes in the exchange rate appear to be explained by order flow. Unfortunately, most of the microstructure literature features order flow as an exogenous variable in a single market setting. Its very origin remains unexplained and open to different interpretations. Market interdependence is generally ignored.

This paper contributes to the existing literature four dimensions. First, we provide a market model in which order flow is the result of belief changes of various investor groups. This allows for a structural interpretation of order flow regressions. Second, we model a two country multi-market setting in which we can explore the relationship between equity, exchange rate and bond markets. In particular, we obtain testable restrictions which link equity returns to the various order flows. Thirdly, we show that our empirical framework explains up to 60 percent of the daily return variations in the S\&P 100 index. In accordance with the theory, both exchange rate returns and order flow in the oversea market have explanatory power for the domestic stock market returns. Fourth, our model can explain the asymmetry in the correlation structure of equity returns and exchange rates. After controlling for order flow, US equity market appreciations typically come with US dollar appreciations, while European equity market returns correlated negatively with Euro appreciations.

What motivates trades through market orders as opposed to limit orders? In most microstructure model of limit order markets those market participants with private asset valuations removed from the current midprice tend to pursue market order strategies. ${ }^{2}$ The intuition is straightforward. Execution uncertainly related to limit order submission is a multiplicative factor for the expected benefit of a trade. In the absence of risk aversion, the probability of non-execution reduces the expected trade benefit linearly as the difference between current midprice and the private value increases. The cost of market order submission by contrast is an additive cost related to the effective spread. It is unchanged by more extreme private asset valuations. A large change in the asset valuation by a segment of market participants will therefore tend to trigger predominantly market orders. This feature or modern limit order markets makes order flow a suitable proxy for (substantial) investor belief changes. Our simple market model captures this aspect, namely order flow is simply a linear function of belief changes. Hence, order flows can be used to identify heterogenous belief changes within a segmented investor population.

Previous work on the relationship between asset returns and order flow has typically been focused on

\footnotetext{
${ }^{1}$ Occasionally, order flow is also refered to as order imbalance.

${ }^{2}$ See for example Harris (1998), Parlour (1998), Foucault (1999), Bias, Martimort, and Rochet (2000). Empirical evidence on the trade-off between execution risk and spread costs is provided by Biais, Hillion and Spatt (1995), Griffiths, Smith, Turnbull, and White (2000), Harris and Hasbrouck (1996). See also Hollifield, Miller and Sandas (2003) for a nonparametric test of the hypothesis that order submission strategies depend on the distance of private asset values from the current midprice.
} 
a single asset market. The focus of our paper is the market interaction between equity and exchange rate markets in a partially segmented international asset market. Recent empirical and theoretical work has emphasized the limited market integration of the global equity market (Karolyi and Stulz (2002), Hau and Rey (2003), Stulz (2005)). The microstructure approach used here can be useful in understanding international market interdependence. Domestic equity returns should not only be highly correlated with domestic order flow, but exchange rate returns and order flow into the oversea market should have additional explanatory power for domestic equity returns. International equity market segmentation implies heterogeneous residual asset supply elasticities for the belief and order flow shocks of domestic versus global market investors. Hence, aggregate home order flow is an insufficient statistics for capturing the home equity return effect. Both exchange rates returns and oversea order flow provide additional explanatory power because they jointly identify the international component of the home order flow which faces a different asset supply elasticity. We highlight that the overall explanatory power is astonishing. For the S\&P100 we are able to explain around 60 percent of the daily return variation and for the CAC40 approximately 40 percent.

Our framework can also explain the asymmetry in the international correlation structure of equity and exchange rate returns. After controlling for equity order flows US equity returns correlate positively with Dollar appreciations, while European equity market returns correlate negatively with Euro appreciations. Again, market segmentation can imply different residual asset supply elasticities in the home and foreign market and so that the same combination of belief shocks by global and local equity investors produces return correlation of opposite sign. Belief shocks by global investors tend to induce a positive correlation, while belief shocks by local investors induce an international substitution effect which generates a negative correlation. If residual supply elasticities differ across countries, so will the correlation structure of equity and exchange rate returns. Finally, we also show that time varying risk premia defined as the deviations from uncovered equity parity can be well explained by our model. This contrasts with the shortcomings of existing models to account for deviations from uncovered interest parity. Uncovered equity parity (Hau and Rey (2003), Derviz (2004)) is the analogue to uncovered interest parity in our model.

Our paper also relates to a recent literature which focuses on the role of order flow in the U.S. equity market. Hasbrouck and Seppi (2001) show that commonality in the order flows of individual stocks explains roughly two-thirds of the commonality in returns. But this paper restricts itself to high frequency intervals. Chordia and Subrahmanyam (2004) study the relationship between order flow and daily returns of individual stocks. Pastor and Stambaugh (2003) find that market wide liquidity is a state variable important for asset pricing at the daily frequency. Chordia, Roll and Subrahmanyam (2002) document for the period 1988 to 1998 that aggregate order flow in the NYSE is correlated with contemporaneous daily S\&P500 returns. But their regressions are not based on any structural model and show much lower explanatory power. To the best of our knowledge, no paper has tried to formally model aggregate equity returns in terms of aggregate equity order flow or related cross country differences in equity order flows to exchange rate movements.

The following section presents the model. Section 3 summarizes and explains the resulting equilibrium relationships. The data is explained in Section 4. Section 5.1 discusses the estimation results for aggregate equity returns and Section 5.2 contain our model estimation for the time varying deviations 
from uncovered equity parity. Section 6 concludes.

\section{The Model}

The model sketched in this section serves several purposes. First, it is designed to represent a multimarket setting in which different types of fund managers experience exogenous belief changes about the fundamental (or terminal) value of home and foreign equity. Our multi-market setting is a stylized representation of a partially integrated international equity and bond market linked through a common foreign exchange market. Secondly, we wish to capture how heterogenous belief changes about equity values trigger order flow in each market and leads to consecutive price changes. ${ }^{3}$ The market structure follows the simultaneous-trade approach (Evans and Lyons (1997, 2002a)) in which market orders precede the price adjustment process. This allows for a clear model-based definition of order flow. Thirdly, we wish to identify a structural relationship between order flow and (empirically unobservable) belief changes. We can then substitute belief changes with order flows and obtain an empirically testable framework relating order flows to market returns.

The multi-market setting features equity and bonds market both at home and abroad. We assume that there are four different types or groups of (atomistic) agents called 'funds'. ${ }^{4}$ These four fund groups are listed in Table 1: International equity funds, investing in home and foreign equity; international bond funds, investing in home and foreign bonds; home country funds, investing in home equity and a home bond and foreign funds, investing in foreign equity and a foreign bond. ${ }^{5}$ Our model therefore features a segmented market in which the exchange rate risk is not diversified. The bonds in both markets are assumed to be in completely price inelastic supply with a constant return in local currency assumed to be $r$ for both home and foreign bonds. ${ }^{6}$ The bond prices are normalized to 1 without loss of generality.

The market structure is illustrated in Figure 1. In round 1 funds quote prices based on their initially rational beliefs about the liquidation value of the asset prices at the end of round 2 . These funds commit to provide liquidity at any quantity of market orders they experience. Next, funds experience belief changes about the liquidation value of equity. They proceed to place market orders which correspond to their optimal position change under the new estimated equilibrium price. The belief change is at that moment private information. Each fund does not know the belief change of the other funds and can only assume that they are unchanged. At the end of round 1, the market orders are executed, at which

\footnotetext{
${ }^{3}$ Survey data suggests that international differences in equity return beliefs are in fact important. Shiller et al. (1996) document large aggregate differences of opinion on the price expectations of the Nikkei and S\&P100 index across Japanese and American fund managers.

${ }^{4}$ To justify competitive price taking behavior, we assume that each investor groups is composed of a continuium of atomistic agents. For the price equilibrium only their aggregate risk tolerance matters. Belief heterogeneity within each group represents a less interesting extension as such heterogeneity will "wash out" under aggregation. We therefore focus on heterogeneity across groups.

${ }^{5}$ We fix notation as follows: the four funds are indicated with the subscripts $h, f, e$ and $b$ for home, foreign, international equity and international bond respectively; the superscripts $H$ and $F$ refer to holdings of home and foreign equities respectively and the superscripts $B^{H}$ and $B^{F}$ refer to holdings of home and foreign bonds respectively.

${ }^{6}$ We do not specify what pins down the riskless rate of interest in the model. In addition, there is no distinction between real and nominal returns. The reader may like to think of the riskless rate as being determined by the rate of time preference or a steady state marginal efficiency of capital. Finally, the assumption that the riskless rate is the same in both countries has no bearing on the results.
} 


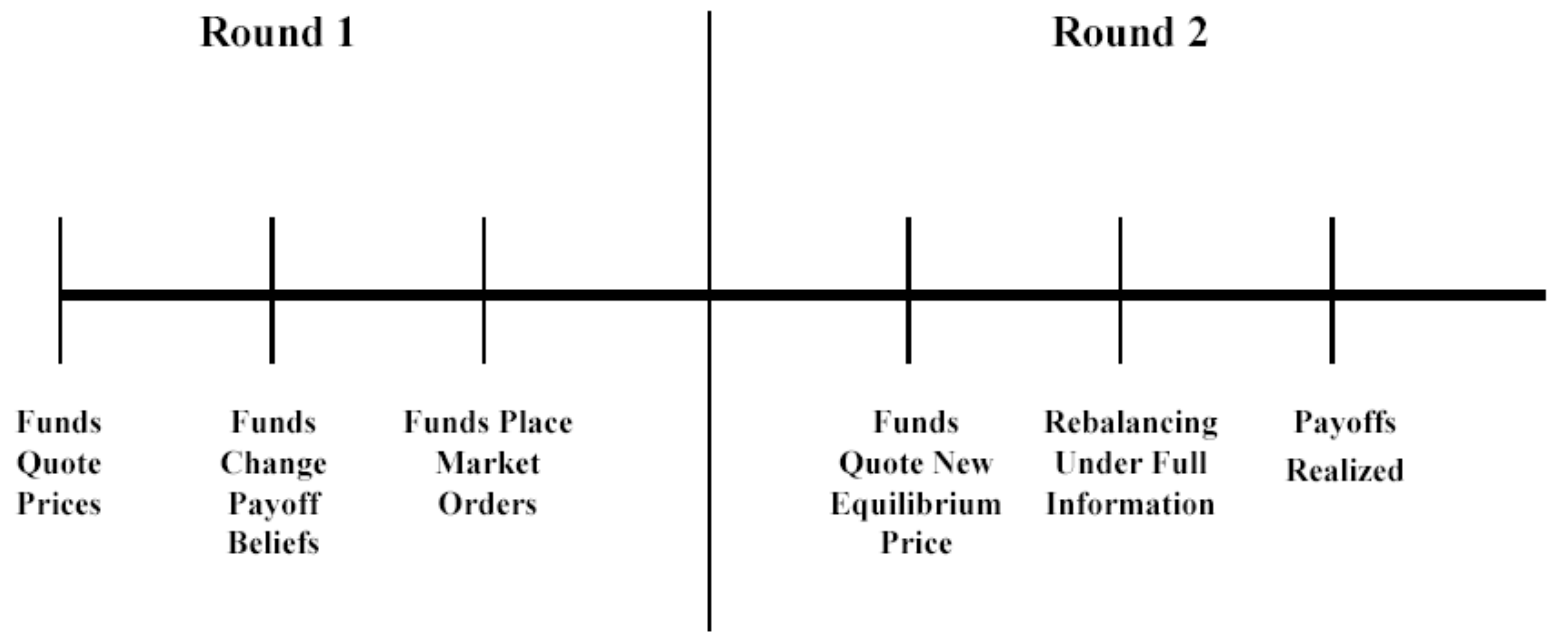

Figure 1: Market Structure

point all transactions become observable. This allows inference about the belief changes of all funds at the beginning of round 2. Under full information, new equilibrium prices are quoted. Since the market orders in round 1 are based on incomplete information, portfolio imbalances still exist. A further round of trading in round 2 leads to the equilibrium allocation of assets before the payoffs are realized. It is important to note that rebalancing under full information in round 2 does not allow any inference about the trade direction. Sell and buy initiated orders are equally likely in all markets.

Let $x_{e}^{H}$ and $x_{e}^{F}$ denote the home and foreign equity market investment of the international fund, respectively, and $x_{h}^{H}$ and $x_{f}^{F}$ the domestic investments of the home and foreign fund. For simplicity, we assume that there are zero net stocks outstanding. The market clearing condition for the equity markets then takes the form

$$
\begin{aligned}
x_{e}^{H}+x_{h}^{H} & =0 \\
x_{e}^{F}+x_{f}^{F} & =0 .
\end{aligned}
$$

The foreign exchange market clears for a demand $x_{e}^{H}$ for home currency on the part of the international equity market and a home currency demand $x_{b}^{B^{H}}$ from the international bond fund. Under zero net balances, we have ${ }^{7}$

$$
x_{e}^{H}+x_{b}^{B^{H}}=0
$$

We assume that all four funds are fully leveraged and that their net asset position is zero. In combination with the zero net equity supply, this assumption implies that we can neglect risk premia in the analysis.

\footnotetext{
${ }^{7}$ We could have equivalently expressed the foreign exchange market clearing condition in terms of the demand for foreign currency.
} 
The exchange rate, $E$, is defined as the ratio of home (U.S.) to foreign currency (Euro), hence an increase in $E$ corresponds to a dollar depreciation.

The investment behavior of the four funds is defined by the following assumption:

\section{Assumption 1: Fund Objectives}

The four groups of investment funds $i=e, b, h, f$ competitively pursue investment objectives which maximize a CARA objective function given by

$$
U_{i}=\mathcal{E}_{i}\left(\Delta \Pi_{i} \mid I\right)-\frac{1}{2} \rho_{i} \operatorname{Var}\left(\Delta \Pi_{i} \mid I\right) .
$$

where the expected net payoffs $\mathcal{E}_{i}\left(\Delta \Pi_{i} \mid I\right)$ and payoff variance $\operatorname{Var}\left(\Delta \Pi_{i} \mid I\right)$ are conditional on equity prices and the exchange rate $\left(I=\left\{P^{H}, P^{F}, E\right\}\right)$ and $1 / \rho_{i}$ denotes the aggregate risk tolerance of each group.

(1) International equity funds $(e)$ choose optimal home and foreign equity holdings $\left(x_{e}^{H}, x_{e}^{F}\right)$ subject to a budget constraint

$$
0=x_{e}^{H} P^{H}+x_{e}^{F} E P^{F}
$$

(2) International bond funds $(b)$ choose optimal home and foreign bond holdings $\left(x_{b}^{B^{H}}, x_{b}^{B^{F}}\right)$ subject to a budget constraint

$$
0=x_{b}^{B^{H}}+E x_{b}^{B^{F}}
$$

(3) Home funds $(h)$ choose optimal home equity and home bond holdings $\left(x_{h}^{H}, x_{h}^{B^{H}}\right)$ subject to the budget constraint

$$
0=x_{h}^{H} P^{H}+x_{h}^{B^{H}}
$$

(4) Foreign funds $(f)$ chooses optimal foreign equity and foreign bond holdings $\left(x_{f}^{F}, x_{f}^{B^{F}}\right)$ subject to the budget constraint

$$
0=x_{f}^{F} P^{F}+x_{f}^{B^{F}}
$$

The mean-variance framework allows for a particularly straightforward closed-form solution. Our main interest is not the steady state solution of the price system, but its reaction to perturbations. In particular, we are interested in the price and order flow effects if each fund manager changes his belief about the fundamental value of equity in a heterogenous manner. We assume a single stochastic belief change around the correct expected liquidation values of equity. Formally, we have:

\section{Assumption 2: Heterogenous Belief Changes}

Managers for the fund types $i=e, b, h, f$ undergo heterogenous (type specific) stochastic belief changes $\boldsymbol{\mu}=\left(\mu_{e}^{H}, \mu_{e}^{F}, \mu_{h}^{H}, \mu_{f}^{F}\right)$ about the liquidation value of home and foreign equity ${ }^{8}$. Starting from initially correct beliefs about the steady state liquidation values $\left(\bar{V}^{H}, \bar{V}^{F}\right)$ of home

\footnotetext{
${ }^{8}$ Obviously, holders of the international bond fund do not suffer from misperceptions about equity prices because they never invest in that asset.
} 
and foreign equity, the new conditional beliefs $\left(I=\left\{P^{H}, P^{F}, E\right\}\right)$ about the fundamental equity value can be expressed as

$$
\begin{aligned}
& \mathcal{E}_{e}\left(V^{H} \mid I\right)=\bar{V}^{H}+\mu_{e}^{H} \\
& \mathcal{E}_{e}\left(V^{F} \mid I\right)=\bar{V}^{F}+\mu_{e}^{F} \\
& \mathcal{E}_{h}\left(V^{H} \mid I\right)=\bar{V}^{H}+\mu_{h}^{H} \\
& \mathcal{E}_{f}\left(V^{F} \mid I\right)=\bar{V}^{F}+\mu_{f}^{F} .
\end{aligned}
$$

Heterogenous belief changes concern only equity valuation. Relative to bonds with predefined cash flows, equity is notorious difficult to value and might therefore be more exposed to belief changes. These belief changes only concern the first moment. The funds hold identical and correct beliefs concerning the variances. The liquidation value of both the home and foreign equity has a variance $\sigma^{2}$ and the liquidation value of currency a variance $\sigma_{E}^{2}$.

\section{Equilibrium Relationships}

The objective function of each fund is defined in terms of mean and variance of the terminal payoff. This allows for simple linear asset demand functions for each fund. Combined with the market clearing condition for the two equity markets and the forex market, we therefore obtain a linear system of three equations which characterizes the equilibrium prices and returns as a function of the belief changes. The three markets in our model are interrelated in the sense that a belief shock in one market affects the equilibrium price in the other two. For example, a positive belief shock for the home fund manager will increase the price of domestic equity. Higher prices in domestic equity induce a substitution effect on the part of the international equity fund, which will increase its demand for foreign equity and reduce its home country equity holdings. This increases the foreign equity price and at the same time increases the demand for foreign exchange balances. The foreign currency will therefore appreciate.

The equilibrium return impact of general belief change on the part of all equity investors is summarized in Proposition 1:

\section{Proposition 1: Returns and Heterogenous Beliefs}

The equilibrium returns $\mathbf{R}=\left(R^{H}, R^{F}, R^{E}\right)$ for home equity, foreign equity, and the exchange rate, respectively are linearly related to belief changes $\boldsymbol{\mu}=\left(\mu_{e}^{H}, \mu_{e}^{F}, \mu_{h}^{H}, \mu_{f}^{F}\right)$ about the home and the foreign equity value according to

$$
\mathbf{A R}=\mathbf{B} \boldsymbol{\mu}
$$

for matrices $\mathbf{A}$ and $\mathbf{B}$ defined as

$$
\mathbf{A}=\left[\begin{array}{ccc}
\left(1+\lambda_{h}\right) & -1 & -1 \\
-1 & \left(1+\lambda_{f}\right) & 1 \\
-1 & 1 & \left(1+\lambda_{b}\right)
\end{array}\right], \quad \mathbf{B}=\frac{1}{1+r}\left[\begin{array}{cccc}
1 & -1 & \lambda_{h} & 0 \\
-1 & 1 & 0 & \lambda_{f} \\
-1 & 1 & 0 & 0
\end{array}\right]
$$


a riskless rate $r$, parameters defined as

$$
\lambda_{h}=\frac{\rho_{e}\left[2 \sigma^{2}+(1+r)^{2} \sigma_{E}^{2}\right]}{\rho_{h} \sigma^{2}}, \quad \lambda_{f}=\frac{\rho_{e}\left[2 \sigma^{2}+(1+r)^{2} \sigma_{E}^{2}\right]}{\rho_{f} \sigma^{2}}, \quad \lambda_{b}=\frac{\rho_{e}\left[2 \sigma^{2}+(1+r)^{2} \sigma_{E}^{2}\right]}{\rho_{b}(1+r)^{2} \sigma_{E}^{2}} .
$$

Proof: See Appendix.

The return vector $\mathbf{R}$ is uniquely determined by the belief changes $\boldsymbol{\mu}$ as long as the matrix $\mathbf{A}$ is non-singular. The three equilibrium equations result directly from the market clearing condition in the home and foreign equity markets and in the foreign exchange market. The belief changes $\mu_{e}^{H}, \mu_{e}^{F}$ for the international equity fund always appear symmetrically in the term $\mathbf{B} \boldsymbol{\mu}$ but with opposite sign, hence only the relative belief of the international equity investor change $\mu_{e}^{H}-\mu_{e}^{F}$ matters for the price determination. The parameters $\lambda_{h}, \lambda_{f}$ and $\lambda_{b}$ denote ratios of asset supply elasticities. For example, $\lambda_{h}$ denotes the aggregate supply elasticity of the home equity investors (proportional to $1 / \rho_{h} \sigma^{2}$ ) relative to the aggregate supply elasticity of the international equity investors. A lower risk aversion of the home investor or lower home price variance imply a more price inelastic home asset supply and therefore a large parameter $\lambda_{h}$. Belief shocks by the international equity fund then have a more modest home return effect. We also note that the belief changes of the home and foreign fund only enter the first and second equation, respectively, while belief change of the international equity fund affects all three market clearing conditions simultaneously.

Exogenous belief changes are the only source of price change in our model. But such belief changes are not directly observable. But in our stylized trading model, belief changes lead directly to market orders and are therefore revealed through order flow. Generally, belief changes create a motive for each fund to rebalance its portfolio. Theoretically, such rebalancing could occur through a passive limit order submission strategy only. The fund which desires to sell equity would try to maintain the most competitive ask price and reduce its position successively over time as this sell offer is repeatedly executed. In this case the belief shift would not translate into a corresponding (negative) order flow. In practice, however, fund managers typically pursue more active strategies by directly submitting market sell orders. Active order placement tends to accelerate the portfolio rebalancing and avoids front running by other investors. The belief change is then clearly associated with a corresponding (negative) order flow. Recent empirical work on order execution strategies indeed confirm that the likelihood of a market order increases with an investors valuation distance from the spread midpoint (Hollifield et al., 2004). This is captured in our model framework. In round 1 funds react to the belief changes with market orders which result in an aggregate order flow stated in the following proposition:

\section{Proposition 2: Equity Order Flows}

Belief changes $\boldsymbol{\mu}=\left(\mu_{e}^{H}, \mu_{e}^{F}, \mu_{h}^{H}, \mu_{f}^{F}\right)$ trigger market orders resulting in equity market order flow $\left(O F^{H}, O F^{F}\right)$ for the home and foreign, respectively, given by

$$
\begin{aligned}
O F^{H} & =k\left[\mu_{h}^{H}+\mu_{e}^{H}-\mu_{e}^{F}\right] \\
O F^{F} & =k\left[\mu_{f}^{F}+\mu_{e}^{F}-\mu_{e}^{H}\right]
\end{aligned}
$$


where the parameters are defined as:

$$
\begin{aligned}
k & =\frac{1}{\Delta} \times \frac{\lambda_{h} \lambda_{f} \lambda_{b}}{\rho_{e}\left\{2 \sigma^{2}+(1+r)^{2} \sigma_{E}^{2}\right\}}>0 \\
\Delta & =\lambda_{h} \lambda_{f} \lambda_{b}+\lambda_{h} \lambda_{f}+\lambda_{h} \lambda_{b}+\lambda_{f} \lambda_{b}
\end{aligned}
$$

Proof: See Appendix.

Order flow in the home and foreign equity market is proportional to the belief change $\mu_{h}^{H}, \mu_{f}^{F}$ of the home and foreign fund, respectively. And in each case order flow depends linearly (with opposite signs) on the relative belief change, $\mu_{e}^{H}-\mu_{e}^{F}$, of the international equity fund. Hence, as for returns, only the relative belief change is identified though the order flow.

The international equity fund is also assumed to practice active order placement in the foreign exchange market as a corollary to its rebalancing in the two equity markets. The rebalancing in the two equity markets depends on its own relative belief change $\mu_{e}^{H}-\mu_{e}^{F}$ as well as belief revision of the local funds $\left(\mu_{h}^{H}, \mu_{f}^{F}\right)$ which translate into local equity price changes. The resulting foreign exchange order flow is given in proposition 3 :

\section{Proposition 3: Foreign Exchange Order Flows}

The international equity fund initiates (in round 1) foreign exchange transactions in order to finance overseas equity investments. Their overseas investment is determined by their belief change relative to the local equity investors, therefore foreign exchange order flow $O F^{E}$ follows as

$$
O F^{E}=k\left[\left(\mu_{e}^{F}-\mu_{e}^{H}\right)\right] .
$$

Proof: See Appendix.

The theoretical linkage between order flow in round 1 and the belief changes allow us to restate the structural model in proposition 1 in terms of observable variables only. In particular, belief changes can be substituted by equity order flows and we obtained a reduced form structure summarized as follows:

\section{Proposition 4: Reduced Form Structure}

The home and foreign equity returns, $R^{H}$ and $R^{F}$, are linearly related to the exchange rate return $R^{E}$ and the home and foreign equity order flows, $O F^{H}$ and $O F^{F}$, according to:

$$
\begin{aligned}
& R^{H}=\frac{1}{3}\left[\left(1+\lambda_{b}\right)+\lambda_{b} \frac{\left(\lambda_{h}-2 \lambda_{f}\right)}{\lambda_{h} \lambda_{f}}\right] R^{E}+\frac{1}{3 k(1+r)}\left(2 O F^{H}+O F^{F}\right) \\
& R^{F}=\frac{1}{3}\left[-\left(1+\lambda_{b}\right)+\lambda_{b} \frac{\left(2 \lambda_{h}-\lambda_{f}\right)}{\lambda_{h} \lambda_{f}}\right] R^{E}+\frac{1}{3 k(1+r)}\left(O F^{H}+2 O F^{F}\right)
\end{aligned}
$$

where $\lambda_{h}, \lambda_{f}, \lambda_{b}>0$ and $k>0$ are the previously defined parameters.

Proof: See Appendix. 
The reduced from implies that both home and foreign equity returns can be represented as a linear combination of the exchange rate return and both home and foreign equity market order flow. The return equations therefore illustrate market interdependence. Moreover, local equity returns are more sensitive to local order flow than the order flow in the overseas equity market.

The coefficients on exchange rate changes are best interpreted as follows. Consider the possibility that risk aversion towards equities is the same for the home and foreign fund. This means that $\lambda_{h}=\lambda_{f}=\lambda$. In this case, the exchange rate coefficient in the home equation is $\frac{1}{3}\left[1+\lambda_{b}(1-1 / \lambda)\right]$ while that in the foreign equation is equal but opposite in sign. Deviations from this symmetry occur when equity supply elasticity (governed by the risk aversion) of the domestic equity fund differs across the two countries. Note that the sum of the two exchange rate coefficients is $\lambda_{b}\left[1 / \lambda_{f}-1 / \lambda_{h}\right]$. If risk aversion for the home equity fund is lower than that of the foreign equity fund, this sum is positive and vice-versa. For $\lambda_{h}=\lambda_{f}=\lambda$, we can then express the sum of the two returns as a linear function of the sum of the two equity order flows only,

$$
R^{H}+R^{F}=\frac{1}{k(1+r)}\left[O F^{H}+O F^{F}\right]
$$

Belief changes by the international equity fund creates off-setting negative and positive order flow and return effects which do not affect the sum of order flow and return. However, this pre-supposes that both equity markets have the same supply elasticities which is not the case under differential risk aversion of the two domestic equity funds. For example, under higher home than foreign risk aversion (or price variance), $\lambda_{f}>\lambda_{h}$, the sum of the equity returns is increased for a negative exchange rate return (dollar appreciation), $R^{E}<0$. Intuitively, this corresponds to a case in which the international equity fund has a positive shock $\mu_{e}^{H}-\mu_{e}^{F}>0$ about home (U.S.) equity and its portfolio rebalancing in favor of home assets appreciates the home currency. Given that the home equity supply is more price elastic than the foreign equity market due to the higher risk aversion of the home fund, price increase in home equity is not fully compensated by the price decrease in for the foreign equity market. This requires an additional adjustment term so that generally

$$
R^{H}+R^{F}=\lambda_{b}\left[\frac{1}{\lambda_{f}}-\frac{1}{\lambda_{h}}\right] R^{E}+\frac{1}{k(1+r)}\left[O F^{H}+O F^{F}\right] .
$$

An important advantage of the reduced form is that it can be directly estimated. Both home and foreign returns may be correlated with the exchange rate return. Moreover, both home and foreign order flow influence both the home and foreign equity returns. We highlight the implication of the model that local order flow has twice the impact on local returns as has the non-local equity order flow.

\section{Data}

An empirical test of the above model would ideally involve many country pairs with developed equity markets. While equity return data is available for almost all countries, the information needed to construct order flow data can only be obtained for a small number of countries. The United States and France are the two largest OECD countries for which individual transaction data on a large part of the domestic equity trading volume is publicly available. We therefore take the U.S. to be the home country and France to be the foreign country. The relevant exchange rate is then the Euro-Dollar rate and we assume that 
the French equity market is representative of the consolidated euro-zone equity market both in terms of returns and order flow characteristics. Our data spans the five year period from January 1999 to December 2003 and therefore start with the creation of the common European currency.

\subsection{U.S. Equity Data}

The U.S. order flow data is constructed from the TAQ database with the help of Wharton Research Data Services. We restrict attention to the stocks in the Standard\&Poors 100 index and accounted for all their trades on AMEX, NASDAQ and NYSE over the 5 year period, approximately 600 million trades in total. All trades are signed as buyer- or seller-initiated depending on whether the executed price was higher or lower than the midpoint between the ask and bid quote respectively. ${ }^{9}$ Trades executed at the mid-point are not signed. The value of all buy trades in all of the 100 stocks in each day are accumulated to create a single aggregate daily buyer-initiated equity trade series for the U.S. Corresponding series are constructed for the seller-initiated and unsigned trades. The raw aggregate home equity order flow series $\left(R O F^{H}\right)$ is then derived as the buyer-initiated series minus the seller-initiated series. Trading volume $\left(V O L^{H}\right)$ is derived as the sum of the buyer-initiated, seller-initiated and the unsigned trades series. We define the aggregate normalized order flow series as the ratio of order flow to volume $\left(O F^{H}\right)$. The home equity returns series $\left(R^{H}\right)$ is the first difference of the log of the New York closing value for the S\&P100. It was obtained from Datastream.

\subsection{French Equity Data}

French order flow data is constructed based on transaction and quote data from Euronext (Données de Marché Historiques). The reference universe consists of all stocks in the French CAC40 index. Again, we use the Lee and Ready (1991) algorithm to sign trades. Analogously to the U.S. data, we obtain daily raw aggregate equity order flow series $\left(R O F^{F}\right)$, daily volume series $\left(V O L^{F}\right)$ and the daily normalized order flow $\left(O F^{F}\right)$. French aggregate daily equity returns $\left(R^{F}\right)$ were defined as difference in the log of the Paris closing price for the CAC40. The French data accounts for approximately 200 million transactions.

Naturally, the home order flow is denominated in U.S. Dollars and the foreign order flow in Euros. We note that the scale of the U.S. market exceeds that of France by almost an order of magnitude. The use of normalized order flow addresses both issues simultaneously as normalized order flow is strictly bounded between -1 and 1 . Normalized order flow is also without currency denomination.

\subsection{Foreign Exchange Data}

Daily foreign exchange order flow was obtained directly from Electronic Broking Services (EBS). There are three types of trades in the forex market: customer-dealer trades, direct inter-dealer trades, and brokered inter-dealer trades. Customers are non-financial firms and non-dealers in financial firms (e.g., corporate treasurers, hedge funds, mutual funds, pension funds, proprietary trading desks, etc.). Dealers are market-makers employed in banks worldwide, of which the largest 10 dealing banks account for more than half of the volume in major currencies.

\footnotetext{
${ }^{9}$ The method used by WRDS restricts itself to quotes that have been in effect for at least five seconds when the trade occurs (see Lee and Ready, 1991).
} 
Our data come from the third trade type: brokered inter-dealer trading. There are two main interdealer broking systems, EBS and Reuters Dealing 2000-2. Both offer competing central market places through electronic terminals. Estimates by the Bank of England (2001) suggest that electronic brokering was used for 66 percent of all transactions in 2001, up from 30 percent in 1998. Similarly, the Federal Reserve Bank of New York (2001) estimates the market share of electronic trading systems at 71 percent in 2001. Discussions with industry specialists indicate that EBS has a two-thirds market share in the brokered inter-dealer dollar-euro market. Our data set includes the daily value of purchases and sales in the dollar-euro market for first year of our sample, 1999. They are measured in millions of Euros. Unlike the equities data, no algorithm was needed to sign trades (ex post) since this occurs electronically at the moment of execution. Each trading day (weekday) covers the 24 hour period starting at 21.00 GMT. The daily raw foreign exchange order flow series $\left(R O F^{E}\right)$ is calculated as the value of buy trades minus the value of sell trades. The daily volume series $\left(V O L^{E}\right)$ represents the sum of the value of buy and sell trades and the daily normalized order flow $\left(O F^{E}\right)$ is again defined as the ratio of $R O F^{E}$ to $V O L^{E}$. The dollar-euro exchange rate at the New York close was obtained from Datastream. It is defined as the dollar price of euro. The daily foreign exchange return $R^{E}$ follows as the difference in the log of the exchange rate level.

Table 2 provides descriptive statistics for the variables used in the estimation. These are the quantity variables, $R O F^{E}, V O L^{E}, O F^{E}, R O F^{F}, V O L^{F}, O F^{F}, R O F^{H}, V O L^{H}, O F^{H}$ and the the three returns, $R^{F}, R^{H}, R^{E}$. For each variable, the table shows the mean, the standard deviation and the first order autocorrelation coefficient.

\section{Estimation Results}

\subsection{The Reduced Form}

Unlike the structural form in Proposition 1, the reduced form in Proposition 4 can be directly estimated. The unobservable belief changes $\boldsymbol{\mu}=\left(\mu_{e}^{H}, \mu_{e}^{F}, \mu_{h}^{H}, \mu_{f}^{F}\right)$ are substituted for order flow variables which proxy for the belief changes. We note, however, that in the system of two equations, the three parameters $\lambda$ cannot be separately identified. Moreover, the identification rests on the assumption that the equity funds undergoing belief changes implement their portfolio change through active order placement strategies. Since we aggregate over a large number of daily transactions in many different stocks to obtain daily order flow, the proxy character of order flow for belief changes should still be preserved if a certain proportion of portfolio change is achieved through passive limit order submission.

Before we estimate the reduced form system, it is instructive to examine how equity returns are affected by own-order flow. Figures 2 and 3 show scatter diagrams for both the U.S. and France. They show a strong positive correlation. This means that equity index returns are strongly related to aggregate or macroeconomic order flow. But our theory asserts much more. Non-local (or overseas) order flow and the exchange rate return also influence the local equity return. In each equation, the equity return is affected by both home and foreign market order flow. Moreover, local equity returns are more sensitive to local order flow than the order flows into the overseas equity market.

Table 3 displays the estimation results. The upper and lower panels show the results for equations 
(1) and (2). The first column reports results using Ordinary Least Squares (OLS). The own-order flow is highly significant in both equations with t-statistics of 27.58 and 16.69 in the home and foreign return equation, respectively. The overseas order flow is also highly significant in both equations with t-statistics of 9.12 and 8.39, respectively. All four order flow coefficient have the correct sign. As predicted by the theory, the magnitude of the coefficient for order flow into the overseas market is less than for own market order flow. The exchange rate return is also significant in both equations. Since both coefficients are negative, we conclude that $\lambda_{f}>\lambda_{h}$. Hence, the asset supply elasticity of domestic relative to international investors is larger for the French than for the U.S. market. ${ }^{10}$ We also note that the $\mathrm{R}^{2}$ in both equations is very high. We succeed in explaining almost $60 \%$ of daily aggregate U.S. stock returns. Ljung-Box Q tests for both equations show that there is no evidence of autocorrelation up to $5^{\text {th }}$ order.

An obvious criticism against the OLS estimation concerns the endogeneity of exchange rate returns, which implies a simultaneity bias for the coefficients. ${ }^{11}$ Finding a suitable instrument for an asset price or its return is generally difficult. However, we know from Evans and Lyons (2002a) that foreign exchange order flow is highly correlated with the exchange rate return. This is confirmed for this particular data set in Hau, Killeen and Moore (2002). We can therefore use foreign exchange order flow as an instrument for the 12 months of 1999. ${ }^{12}$ Estimation proceeds by Two Stage Least Squares (2SLS). Columns 3 and 4 give both the OLS and the 2SLS estimates for the year 1999. Comparing the two sets of estimates for equation 1, it is hard to find any difference between the OLS and 2SLS cases for the first year of the sample. This is formally confirmed by the result of the Hausmann specification test in the upper panel. For the foreign returns equation, the only estimate that appears to change is the exchange rate returns coefficient. Nevertheless, it is still negative and significant and again the Hausmann specification test rejects the endogeneity of the exchange rate, at least for this instrument. We conclude that the OLS estimates for the full sample are confirmed by the instrumental variable procedure. ${ }^{13}$

Next, we examine the intertemporal robustness of the return equations. The last line in each of the panels of Table 3 reports the Chow tests on the parameters between 1999 and the rest of the sample. In the upper panel, the estimated coefficients on both the exchange return and foreign order flow appear to be stable. However, the price impact of home equity order flow is smaller for 1999 than for the whole sample. But it is still large, positive and significant. A formal Chow test confirms the absence of intertemporal instability for the U.S. returns equation. For the foreign returns equation, the exchange rate return coefficient is also stable, but both order flow coefficients are smaller in 1999. The upward trend for the order flow coefficients is confirmed by the rejection of the stability assumption underlying the Chow test. Despite this unfavorable statistical result, it is difficult to argue that the 1999 sub-period displays any economically significant difference relative to the whole sample period.

Finally, we confront the data with the exact parameter restrictions of our parsimonious model. The

\footnotetext{
${ }^{10} \mathrm{~A}$ narrow interpretation within the two country framework would be that the French domestic investor is less risk averse than the U.S. domestic investor. More general, we could conclude that the importance of international investors relative to domestic investors in the U.S. market is bigger than for the French market.

${ }^{11}$ Killeen, Lyons and Moore (forthcoming, 2005) show that order flow is weakly exogenous with respect to exchange rate returns. Secondly, they show that order flow is also strongly exogenous with respect to exchange rate returns. Finally, they show strict exogeneity (exchange rate and order flow innovations are orthogonal).

${ }^{12}$ The data on foreign exchange order flow is available only for the first year of the sample.

${ }^{13}$ We also extimated the two equations as a system using Seemingly Unrelated Regressions (SUR). It makes almost no difference to neither the estimated coefficients nor the standard errors.
} 
own order flow coefficient should be precisely twice the overseas order flow coefficient in both equations. Furthermore, the equivalent coefficients should be the same in both equations. Obviously, the point estimates do not observe these restrictions. A straightforward Wald Test yields a $\chi^{2}(3)$ test statistic of 397.66. This is a statistically very strong rejection of the parameter restrictions on order flow. ${ }^{14}$ But it is natural to ask if model estimation under the exact theoretical parameter restrictions preserves considerable explanatory power for equity returns. In column 2 of Table 3, we show the results of estimating both the home and foreign return equation jointly using Seemingly Unrelated Regressions (SUR). Both the within and cross equation restrictions are now imposed. The explanatory power in the French equation is barely affected by the restrictions, while the $R^{2}$ for U.S. return falls to just under 47 percent. The restricted order flow coefficients have the theoretically correct sign and remain statistically and economically significant. The exchange rate coefficients are also still negative and statistically significant. It is interesting to note that the sum of the exchange rate coefficients is essentially the same under the restricted and unrestricted model estimation. Hence both procedures produce the same implication for the relationship between risk aversions of domestic investors at home and in the foreign country.

\subsection{Deviations from Uncovered Equity Parity}

The equations in proposition 4 can be easily transformed into an expression for the analogue to uncovered interest parity for equities, namely uncovered equity returns parity (Derviz (2004), Hau and Rey (2003)). The uncovered equity parity terms $R^{H}-R^{F}-R^{E}$ captures the excess return (in home currency terms) of a simultaneous long and short position in home and foreign equity, respectively. The model predicts how deviations from uncovered equity market relate to exchange rate returns itself and order flow differences across both equity markets. Formally,

$$
R^{H}-R^{F}-R^{E}=\frac{1}{3} \gamma R^{E}+\frac{1}{3 k(1+r)}\left[O F^{H}-O F^{F}\right]
$$

with

$$
\gamma=-1+\lambda_{b}\left\{2-\frac{\left(\lambda_{h}+\lambda_{f}\right)}{\lambda_{h} \lambda_{f}}\right\}
$$

The exchange rate return appears on the right hand side and its sign is ambiguous. The results of estimating the above equation are displayed in the first column of Table 4. The striking feature is that the $\mathrm{R}^{2}$ is high at 40 percent. All three explanatory variables are highly significant and the equity order flow variables both have the sign predicted by theory.

Theories of uncovered interest parity typically find it difficult to explain why the interest differential $i^{H}-i^{F}$ is uncorrelated with the exchange rate changes. In fact risk premia defined as the deviations $i^{H}-i^{F}-R^{E}$ from uncovered interest parity are very difficult to explain empirically. Our model provides a simple closed form characterization of the time-varying risk premium which mark deviations from uncovered equity parity.

Equation (5) can be restated by substituting for the exchange rate return on the right hand side. We can express the exchange rate return as

$$
R^{E}=\left[\rho_{b}(1+r) \sigma_{E}^{2}\right] k\left[\left(\mu_{h}^{H}-\mu_{f}^{F}\right)-\left(\mu_{e}^{H}-\mu_{e}^{F}\right)\right],
$$

\footnotetext{
${ }^{14}$ The $1 \%$ critical value is 11.345
} 
and using proposition 3 we obtain directly

$$
R^{E}=\left[\rho_{b}(1+r) \sigma_{E}^{2}\right] O F^{E}+\varepsilon
$$

where $\varepsilon=\left[\rho_{b}(1+r) \sigma_{E}^{2}\right] k\left(\mu_{h}^{H}-\mu_{f}^{F}\right)$. The exchange rate returns is directly proportional to foreign exchange order flow $O F^{E}$. We can therefore give a fresh structural interpretation of the Evans and Lyons (2002a) expression for the price impact of order flow. The price or return impact is governed by the parameter $\left[\rho_{b}(1+r) \sigma_{E}^{2}\right]$, which depends on the volatility of the exchange rate returns and risk aversion $\rho_{b}$ of the international bond funds which provide the liquidity in the foreign exchange market.

Substituting in for the exchange rate return

$$
R^{E}=\rho_{b}(1+r) \sigma_{E}^{2}\left[3 O F^{E}+\left(O F^{H}-O F^{F}\right)\right]
$$

on the right hand side of equation (5), we obtain

$$
R^{H}-R^{F}-R^{E}=\rho_{b}(1+r) \sigma_{E}^{2} \gamma O F^{E}+\left[\frac{1}{3} \rho_{b}(1+r) \sigma_{E}^{2} \gamma+\frac{1}{3 k(1+r)}\right]\left[O F^{H}-O F^{F}\right] .
$$

Deviations from uncovered equity returns parity can be explained by three order flows, namely foreign exchange order flow with a negative sign, home equity order flow with a positive sign and foreign equity order flow with equal but opposite negative sign. The results are shown in Table 3 . The $R^{2}$ is almost 40 percent, all variables are very significant and have the correct sign. ${ }^{15}$

We conclude that order flow in the three markets has considerable explanatory power for time varying risk premia. The empirical fit of the model surpasses by far previous attempts to explain similar time varying risk premia for uncovered interest parity. On the other hand, our framework relates the order flows directly to heterogenous belief changes and therefore allows for a coherent interpretation of these order flows instead of taking them as exogenous like in much of the microstructure literature.

\section{Conclusion}

We presented a model in which equity order flow is the expression of heterogenous belief shifts by different investors. The multimarket setting provides not only for enough observable prices and order flows to identify heterogenous belief shifts, but it also implies testable restrictions for international market interdependence. We derived a closed-form solution for equity returns in both equity markets, which relates equity returns to the exchange rate and to order flows in both the local and the overseas market. The model can explain asymmetry across countries in the correlations between domestic equity returns and the exchange rate return conditional on order flows.

We confront the model with 5 years of daily U.S. and French equity data. The respective daily order flows for the S\&P100 and the CAC40 index are constructed based on the aggregation of approximately 800 million individual equity transactions. We find that an extraordinarily high percentage of aggregate equity return variation is explained jointly by exchange rate returns and macroeconomic order flows. Our model can explain approximately 60 percent of the daily variation in the S\&P100 return and 40 percent

\footnotetext{
${ }^{15}$ The only feature which contradicts the theory is that the coefficient on French equity order flow is lower in absolute value than that on U.S. equity order flow. Nevertheless the results are encouraging.
} 
of the CAC40 return fluctuations. As predicted by theory, both returns are strongly and positively influenced not only by own market order flow, but also by the order flow in the overseas market. Finally, we show that time varying risk premia, defined as the deviations from uncovered equity parity, are also well explained by the model. In summary, heterogenous belief changes as identified by order flows provide a promising paradigm for future research on equity index movements, exchange rates and international financial market interdependence.

\section{References}

[1] Bank of England, 2001, Triennial Survey of the Foreign Exchange Market.

[2] Chordia, T., R. Roll and A. Subrahmanyam (2002). "Order Imbalance, Liquidity and Market Returns", Journal of Financial Economics, 65, 111-130.

[3] Chordia, T., and A. Subrahmanyam (2004). "Order Imbalance and Individual Stock Returns: Theory and Evidence", Journal of Financial Economics, 72, 485-518.

[4] Derviz, A., 2004, "Asset return dynamics and the FX risk premium in a decentralized dealer market", European Economic Review, 48(4), 747-784.

[5] Evans, M., and R. Lyons, 2002a, "Order Flow and Exchange Rate Dynamics", Journal of Political Economy, 110(1), 170-80.

[6] Evans, M., and R. Lyons, 2002b, "Time-Varying Liquidity in Foreign Exchange", Journal of Monetary Economics, 2002, 49(5), 1025-1051.

[7] Evans, M., and R. Lyons, 2002c, "Informational Integration and FX Trading", Journal of International Money and Finance, 21(6), 807-831.

[8] Federal Reserve Bank of New York, 2001, Triennial Survey of the Foreign Exchange Market.

[9] Frankel, J., and A. Rose, 1995, "Empirical Research on Nominal Exchange Rates", in G. Grossman and K.Rogoff (eds.), Handbook of International Economics, North-Holland.

[10] Hasbrouck, J., and D. Seppi, 2001, "Common Factors in Prices, Order Flows, and Liquidity", Journal of Financial Economics, 59(3), 383-411.

[11] Hau, H., W. Killeen, and M. Moore, 2002. "How Has the Euro Changed the Foreign Exchange Market?", Economic Policy, 34, 151-177.

[12] Hau, H., and H. Rey, 2003, "Exchange Rates, Equity Prices and Capital Flows", Review of Financial Studies, forthcoming.

[13] Hau, H., and H. Rey, 2004, "Can Portfolio Rebalancing Explain the Dynamics of Equity Returns, Equity Flows, and Exchange Rates?", American Economic Review, 96(2), 126-133.

[14] Hau, H., and H. Rey, 2005, "What Drives International Equity Reallocations", memo. 
[15] Hollifield, B., R. Miller, and P. Sandas, 2004, "Empirical Analysis of Limit Order Markets", forthcoming in the Review of Economic Studies.

[16] Karolyi, A., and R. Stulz, 2003, "Are Financial Assets Priced Locally or Globally?", Handbook of the Economics of Finance, Volume 1B, North-Holland, 975-1020.

[17] Lee, Ch., and M. Ready, 1991, "Inferring Trade Direction from Intraday Data", Journal of Finance, 46(2), 733-46.

[18] Pastor, L., and R. F. Stambaugh, 2003, "Liquidity Risk and Expected Stock Returns", Journal of Political Economy, 111, 642-685.

[19] Rogoff, K., 2001, "The Failure of Empirical Exchange Rate Models: No Longer New but Still True", Economic Policy Web Essay, October 2001, Issue 1, volume 1.

[20] Shiller, R. J., Kon-Ya., F., and Y. Tsutsui, 1996, "Why Did the Nikkei Crash? Expanding the Scope of Expecations Data Collection", Review of Economics and Statistics, 78(1), 156-64.

[21] Stulz, R., 2005, "The Limits of Financial Globalization", National Bureau of Economic Research, Inc, NBER Working Papers: 11070. 


\section{Appendix}

\section{Proposition 1: Returns and Heterogenous Beliefs}

The four investment funds $i=e, b, h, f$ pursue investment objectives which maximize a CARA objective function. For normally distributed payoff this simplifies to a utility function in conditional mean and conditional variance of the payoff. In general, for price changes $\Delta P_{1}$ and $\Delta P_{2}$ in two assets and corresponding asset holdings $x_{1}$ and $x_{2}$ the payoff is given by $\Delta \Pi=x_{1} \Delta P_{1}+x_{2} \Delta P_{2}$. For a budget constraint $x_{1} P_{1}+x_{2} P_{2}=0$, we obtain $\Delta \Pi=x_{1}\left[\Delta P_{1}-\frac{P_{1}}{P_{2}} \Delta P_{2}\right]$ and the optimal asset demand can be stated as

$$
x_{1}=\frac{\mathcal{E}\left(\Delta P_{1}-\frac{P_{1}}{P_{2}} \Delta P_{2} \mid I\right)}{\rho \operatorname{Var}\left(\Delta P_{1}-\frac{P_{1}}{P_{2}} \Delta P_{2} \mid I\right)} .
$$

where $\mathcal{E}(. \mid I)$ denotes conditional expectation, $\operatorname{Var}(. \mid I)$ the conditional variance and $\rho$ the coefficient of absolute risk aversion.

We solve the model by first considering the full information price equilibrium which arises in round 2 . At this stage, the belief changes of all funds are public information and this allows for a straightforward calculation of the equilibrium price. Let $V^{H}, V^{F}$ and $V^{E}$ denote the liquidation value of the home equity, the foreign equity and the foreign currency respectively. The corresponding equilibrium prices are $P^{H}, P^{F}$ and $E$. For the home and foreign equity fund, the second asset is a bond with a unit price $\left(P_{2}=1\right)$ and a return $\Delta P_{2}=r$. Hence, their optimal asset demands are given by

$$
\begin{gathered}
x_{h}^{H}=\frac{\mathcal{E}_{f}\left[V^{H}-P^{H}-P^{H} r^{H} \mid I\right]}{\rho_{h} \operatorname{Var}_{h}\left(V^{H} \mid I\right)}=\frac{\bar{V}^{H}+\mu_{h}^{H}-\left(1+r^{H}\right) P^{H}}{\rho_{h} \sigma^{2}} \\
x_{f}^{F}=\frac{\mathcal{E}_{f}\left[V^{F}-P^{F}-P^{F} r^{F} \mid I\right]}{\rho_{f} \operatorname{Var}_{f}\left(V^{F} \mid I\right)}=\frac{\bar{V}^{F}+\mu_{f}^{F}-\left(1+r^{F}\right) P^{F}}{\rho_{f} \sigma^{2}} .
\end{gathered}
$$

For the international equity fund the payoff is given by

$$
\Delta \Pi_{e}=x_{1}\left[\Delta P_{1}-\frac{P_{1}}{P_{2}} \Delta P_{2}\right]=x_{e}^{H}\left[V^{H}-P^{H}-\frac{P^{H}}{E P^{F}}\left(V^{E} V^{F}-E P^{F}\right)\right] .
$$

For steady state values $\bar{V}^{H}, \bar{P}^{H}, \bar{V}^{E}, \bar{E}, \bar{V}^{F}, \bar{P}^{F}$, we can linearize the excess return on home equity as

$$
\begin{aligned}
& V^{H}-P^{H}-\frac{P^{H}}{E P^{F}}\left(V^{E} V^{F}-E P^{F}\right)= \\
& \left(V^{H}-\bar{V}^{H}\right)-\left(P^{H}-\bar{P}^{H}\right)-\frac{\bar{V}^{E} \bar{V}^{F}-\overline{E P} \bar{P}^{F}}{\bar{P}^{F}}\left(P^{H}-\bar{P}^{H}\right)+\frac{\bar{V}^{E} \bar{V}^{F} \bar{P}^{H}}{\bar{E}\left(\bar{P}^{F}\right)^{2}}\left(P^{F}-\bar{P}^{F}\right)+ \\
& +\frac{\bar{V}^{E} \bar{V}^{F} \bar{P}^{H}}{(\bar{E})^{2} \bar{P}^{F}}(E-\bar{E})-\frac{\bar{V}^{F} \bar{P}^{H}}{\overline{E P}}\left(V^{E}-\bar{V}^{E}\right)-\frac{\bar{V}^{E} \bar{P}^{H}}{\overline{E P}^{F}}\left(V^{F}-\bar{V}^{F}\right)= \\
& \left(V^{H}-\bar{V}^{H}\right)-\frac{\bar{V}^{F}}{\bar{P}^{F}}\left(P^{H}-\bar{P}^{H}\right)+\frac{\bar{V}^{F}}{\bar{P}^{F}}\left(P^{F}-\bar{P}^{F}\right)+\bar{V}^{F}(E-1)-\bar{V}^{F}\left(V^{E}-1\right)-\left(V^{F}-\bar{V}^{F}\right) .
\end{aligned}
$$

The final equality is obtained (for reasons of model symmetry ${ }^{16}$ ) by using $\bar{V}^{H}=\bar{V}^{F}, \bar{V}^{E}=\bar{E}=1, \bar{P}^{H}=$ $\bar{P}^{F}$. For the international equity fund the optimal asset demand follows as

\footnotetext{
${ }^{16}$ There is one asymmetry in the model. This is the choice of currency in which the international fund is denominated. However, this has a second order impact on the model. We abstract from this.
} 


$$
\begin{aligned}
x_{e}^{H} & =\frac{\mathcal{E}_{i}\left[\left(V^{H}-\bar{V}^{H}\right)-\left(V^{F}-\bar{V}^{F}\right)-\frac{\bar{V}^{F}}{\bar{P}^{F}}\left(P^{H}-\bar{P}^{H}\right)+\frac{\bar{V}^{F}}{P^{F}}\left(P^{F}-\bar{P}^{F}\right)+\bar{V}^{F}(E-1)-\bar{V}^{F}\left(V^{E}-1\right) \mid I\right]}{\rho_{e} \operatorname{Var}_{e}\left(\left(V^{H}-\bar{V}^{H}\right)-\bar{V}^{F}\left(V^{E}-1\right)-\left(V^{F}-\bar{V}^{F}\right) \mid I\right)} \\
& =\frac{\mu_{e}^{H}-\mu_{e}^{F}-\frac{\bar{V}^{F}}{\bar{P}^{F}}\left(P^{H}-\bar{P}^{H}\right)+\frac{\bar{V}^{F}}{\bar{P}^{F}}\left(P^{F}-\bar{P}^{F}\right)+\bar{V}^{F}(E-1)}{\rho_{e}\left\{2 \sigma^{2}+\left(\bar{V}^{F}\right)^{2} \sigma_{E}^{2}\right\}}
\end{aligned}
$$

For the international bond fund, the payoff is given by

$$
\Delta \Pi_{b}=x_{b}^{H}\left[r^{H}-\frac{1}{E}\left(V^{E}\left(1+r^{F}\right)-E\right)\right] \approx x_{b}^{H}(1+r)\left(E-V^{E}\right),
$$

where bond prices are normalized to 1 and $r^{H}=r^{F}=r$. The optimal demand of the international bond investor follows as

$$
x_{b}^{B^{H}}=\frac{\mathcal{E}_{b}\left[(1+r)\left(E-V^{E}\right) \mid I\right]}{\rho_{b} \operatorname{Var}_{b}\left((1+r)\left(E-V^{E}\right) \mid I\right)}=\frac{E-1}{\rho_{b}(1+r) \sigma_{E}^{2}} .
$$

The steady state (marked by upper bars) follows for $\mu_{e}^{H}=\mu_{e}^{F}=\mu_{h}^{H}=\mu_{f}^{F}=0$. Then market clearing implies

$$
0=\frac{\bar{V}^{F}(\bar{E}-1)}{\rho_{e}\left\{2 \sigma^{2}+\left(\bar{V}^{F}\right)^{2} \sigma_{E}^{2}\right\}}+\frac{\bar{V}^{H}-(1+r) P^{H}}{\rho_{h} \sigma^{2}} .
$$

Inspection of the above equation reveals that $\bar{V}^{H}=(1+r) \bar{P}^{H}, \bar{V}^{F}=(1+r) \bar{P}^{F}$ and $\bar{E}=1$ is a solution. This implies $\bar{x}_{h}^{H}=\bar{x}_{e}^{H}=0$ and from the budget constraint of the international equity fund, $x_{e}^{H} P^{H}+x_{e}^{F} E P^{F}=0$, we get $\bar{x}_{e}^{F}=\bar{x}_{f}^{F}=0$. Therefore $\bar{V}^{F}=(1+r) \bar{P}^{F}$. We can further simplify by setting $\bar{P}^{H}=\bar{P}^{F}=1$. Finally, we can also derive a simple expression for the international equity fund's foreign equity demand, $x_{i}^{F}$. From its budget constraint, we get through linearization around the steady state holdings $\left(\bar{x}_{e}^{H}=\bar{x}_{e}^{F}=0\right)$ directly

$$
x_{e}^{F}=-x_{e}^{H} \frac{\bar{P}^{H}}{\overline{E P}^{F}}=-x_{e}^{H} .
$$

Next we solve for the equilibrium prices $P^{H}, P^{F}$ and $E$ under general belief changes $\mu=\left(\mu_{e}^{H}, \mu_{e}^{F}, \mu_{h}^{H}, \mu_{f}^{F}\right)$. Market clearing in the two equity markets implies,( using 1, A1, A2, A3 and A5 )

$$
\begin{aligned}
0 & =x_{e}^{H}+x_{h}^{H}= \\
& =\frac{\mu_{e}^{H}-\mu_{e}^{F}-(1+r)\left(P^{H}-1\right)+(1+r)\left(P^{F}-1\right)+(1+r)(E-1)}{\rho_{e}\left\{2 \sigma^{2}+(1+r)^{2} \sigma_{E}^{2}\right\}}+\frac{\bar{V}^{H}+\mu_{h}^{H}-(1+r) P^{H}}{\rho_{h} \sigma^{2}} \\
0 & =x_{e}^{F}+x_{f}^{F}= \\
& =-\frac{\mu_{e}^{H}-\mu_{e}^{F}-(1+r)\left(P^{H}-1\right)+(1+r)\left(P^{F}-1\right)+(1+r)(E-1)}{\rho_{e}\left\{2 \sigma^{2}+(1+r)^{2} \sigma_{E}^{2}\right\}}+\frac{\bar{V}^{F}+\mu_{f}^{F}-(1+r) P^{F}}{\rho_{f} \sigma^{2}} .
\end{aligned}
$$


Market clearing in the currency market occurs between the two international funds and yields, (using 2, A3 and A5)

$$
0=x_{e}^{H}+x_{b}^{B^{H}}=\frac{\mu_{e}^{H}-\mu_{e}^{F}-(1+r)\left(P^{H}-1\right)+(1+r)\left(P^{F}-1\right)+(1+r)(E-1)}{\rho_{e}\left\{2 \sigma^{2}+(1+r)^{2} \sigma_{E}^{2}\right\}}+\frac{E-1}{\rho_{b}(1+r) \sigma_{E}^{2}} .
$$

It is straightforward to show that in the absence of any belief changes $\left(\mu_{e}^{H}=\mu_{e}^{F}=\mu_{h}^{H}=\mu_{f}^{F}=0\right)$, the equilibrium price is given by the unit vector, $\mathbf{P}_{0}=\left(P_{0}^{H}, P_{0}^{F}, E_{0}\right)=(1,1,1)$. Note that these represent the optimal price quotes at the beginning of round 1 . In round 2 , however, the equilibrium price depends on the realized belief changes.

We define strictly positive parameters

$$
\lambda_{h}=\frac{\rho_{e}\left[2 \sigma^{2}+(1+r)^{2} \sigma_{E}^{2}\right]}{\rho_{h} \sigma^{2}}, \quad \lambda_{f}=\frac{\rho_{e}\left[2 \sigma^{2}+(1+r)^{2} \sigma_{E}^{2}\right]}{\rho_{f} \sigma^{2}}, \quad \lambda_{b}=\frac{\rho_{e}\left[2 \sigma^{2}+(1+r)^{2} \sigma_{E}^{2}\right]}{\rho_{b}(1+r)^{2} \sigma_{E}^{2}} .
$$

For asset returns $R^{H}=P^{H}-1, R^{F}=P^{F}-1$ and $R^{E}=E-1$ between the initial state and the full information price equilibrium of round 2 , we obtain a linear system of three equations given by

$$
\left[\begin{array}{ccc}
\left(1+\lambda_{h}\right) & -1 & -1 \\
-1 & \left(1+\lambda_{f}\right) & 1 \\
-1 & 1 & \left(1+\lambda_{b}\right)
\end{array}\right]\left[\begin{array}{c}
R^{H} \\
R^{F} \\
R^{E}
\end{array}\right]=\frac{1}{1+r}\left[\begin{array}{c}
\mu_{e}^{H}-\mu_{e}^{F}+\mu_{h}^{H} \lambda_{h} \\
\mu_{e}^{F}-\mu_{e}^{H}+\mu_{f}^{F} \lambda_{f} \\
\mu_{e}^{F}-\mu_{e}^{H}
\end{array}\right]
$$

The return vector $\mathbf{R}=\left(R^{H}, R^{F}, R^{E}\right)$ can then be expressed linearly in terms of belief changes $\boldsymbol{\mu}=$ $\left(\mu_{e}^{H}, \mu_{e}^{F}, \mu_{h}^{H}, \mu_{f}^{F}\right)$ as $\mathbf{R}=\mathbf{A}^{-1} \mathbf{B} \boldsymbol{\mu}$. This proves proposition 1 .

\section{Proposition 2: Equity Order Flow}

At the end of round 1, funds place market orders based on their private knowledge of their own belief change. In the absence of knowledge about other belief changes, they can only assume that those are zero. Accordingly, their optimal market orders are based on an expected equilibrium price which only accounts for the own belief change. Order flow in the home equity market if given as the sum $O F^{H}=O F_{h}^{H}+O F_{e}^{H}$ of the order flow by the home and international fund. Similarly we have $O F^{F}=O F_{f}^{F}+O F_{e}^{F}$.

The order flow of each fund is given for return functions $R^{H}\langle\rangle,. R^{F}\langle$.$\rangle , and R^{E}\langle$.$\rangle by$

$$
\begin{aligned}
O F_{h}^{H} & =\frac{\mu_{h}^{H}-(1+r) R^{H}\left\langle\mu_{h}^{H}\right\rangle}{\rho_{h} \sigma^{2}}=x_{h}^{H}, \text { for } \mu_{f}^{F}=\mu_{e}^{H}=\mu_{e}^{F}=0(\text { from A1) } \\
O F_{f}^{F} & =\frac{\mu_{h}^{F}-(1+r) R^{F}\left\langle\mu_{f}^{F}\right\rangle}{\rho_{f} \sigma^{2}}=x_{f}^{F}, \text { for } \mu_{h}^{H}=\mu_{e}^{H}=\mu_{e}^{F}=0(\text { from A2) } \\
O F_{e}^{H} & =\frac{\mu_{e}^{H}-\mu_{e}^{F}-(1+r)\left(R^{H}\left\langle\mu_{e}^{H}-\mu_{e}^{F}\right\rangle\right)+(1+r)\left(R^{F}\left\langle\mu_{e}^{H}-\mu_{e}^{F}\right\rangle\right)+(1+r) R^{E}\left\langle\mu_{e}^{H}-\mu_{e}^{F}\right\rangle}{\rho_{e}\left\{2 \sigma^{2}+(1+r)^{2} \sigma_{E}^{2}\right\}}= \\
& =x_{e}^{H}, \text { for } \mu_{h}^{H}=\mu_{f}^{F}=0\left(\text { from A3) } \rho_{e}\left\{2 \sigma^{2}+(1+r)^{2} \sigma_{E}^{2}\right\}\right. \\
O F_{e}^{F} & =-\frac{\mu_{e}^{H}-\mu_{e}^{F}-(1+r)\left(R^{H}\left\langle\mu_{e}^{H}-\mu_{e}^{F}\right\rangle\right)+(1+r)\left(R^{F}\left\langle\mu_{e}^{H}-\mu_{e}^{F}\right\rangle\right)+(1+r) R^{E}\left\langle\mu_{e}^{H}-\mu_{e}^{F}\right\rangle}{=}= \\
& =x_{e}^{F}, \text { for } \mu_{h}^{H}=\mu_{f}^{F}=0(\text { from A5) }
\end{aligned}
$$


The equilibrium returns are given by

$$
\begin{aligned}
R^{H} & =\frac{\lambda_{f} \lambda_{e}}{(1+r) \Delta}\left(\mu_{e}^{H}-\mu_{e}^{F}\right)+\frac{\lambda_{h}\left\{\left(1+\lambda_{f}\right)\left(1+\lambda_{e}\right)-1\right\}}{(1+r) \Delta} \mu_{h}^{H}+\frac{\lambda_{e} \lambda_{f}}{(1+r) \Delta} \mu_{f}^{F} \\
R^{F} & =\frac{-\lambda_{h} \lambda_{e}}{(1+r) \Delta}\left(\mu_{e}^{H}-\mu_{e}^{F}\right)+\frac{\lambda_{e} \lambda_{h}}{(1+r) \Delta} \mu_{h}^{H}+\frac{\lambda_{f}\left\{\left(1+\lambda_{e}\right)\left(1+\lambda_{h}\right)-1\right\}}{(1+r) \Delta} \mu_{f}^{F} \\
R^{E} & =\frac{-\lambda_{f} \lambda_{h}}{(1+r) \Delta}\left(\mu_{e}^{H}-\mu_{e}^{F}\right)+\frac{\lambda_{h} \lambda_{f}}{(1+r) \Delta}\left(\mu_{h}^{H}-\mu_{f}^{F}\right)
\end{aligned}
$$

and return expectations, given the funds' private information at the end of round 1, are given by

$$
\begin{aligned}
R^{H}\left\langle\mu_{h}^{H}\right\rangle & =\frac{\lambda_{h}\left\{\left(1+\lambda_{f}\right)\left(1+\lambda_{b}\right)-1\right\}}{(1+r) \Delta} \mu_{h}^{H}=R^{H}, \text { for } \mu_{f}^{F}=\mu_{e}^{H}=\mu_{e}^{F}=0 \\
R^{F}\left\langle\mu_{f}^{F}\right\rangle & =\frac{\lambda_{f}\left\{\left(1+\lambda_{h}\right)\left(1+\lambda_{b}\right)-1\right\}}{(1+r) \Delta} \mu_{f}^{F}=R^{F}, \text { for } \mu_{h}^{H}=\mu_{e}^{H}=\mu_{e}^{F}=0 \\
R^{H}\left\langle\mu_{e}^{H}-\mu_{e}^{F}\right\rangle & =\frac{\lambda_{f} \lambda_{b}}{(1+r) \Delta}\left(\mu_{e}^{H}-\mu_{e}^{F}\right)=R^{H}, \text { for } \mu_{h}^{H}=\mu_{f}^{F}=0 \\
R^{F}\left\langle\mu_{e}^{H}-\mu_{e}^{F}\right\rangle & =\frac{-\lambda_{h} \lambda_{b}}{(1+r) \Delta}\left(\mu_{e}^{H}-\mu_{e}^{F}\right)=R^{F}, \text { for } \mu_{h}^{H}=\mu_{f}^{F}=0 \\
R^{E}\left\langle\mu_{e}^{H}-\mu_{e}^{F}\right\rangle & =\frac{-\lambda_{f} \lambda_{h}}{(1+r) \Delta}\left(\mu_{e}^{H}-\mu_{e}^{F}\right)=R^{E}, \text { for } \mu_{h}^{H}=\mu_{f}^{F}=0
\end{aligned}
$$

We obtain the equity order flows (demands at the end of round 1) as

$$
\begin{aligned}
O F^{H} & =k\left[\mu_{h}^{H}+\mu_{e}^{H}-\mu_{e}^{F}\right] \\
O F^{F} & =k\left[\mu_{f}^{F}+\mu_{e}^{F}-\mu_{e}^{H}\right]
\end{aligned}
$$

where we defined

$$
\begin{aligned}
k & =\frac{1}{\Delta} \times \frac{\lambda_{h} \lambda_{f} \lambda_{b}}{\rho_{e}\left\{2 \sigma^{2}+(1+r)^{2} \sigma_{E}^{2}\right\}}>0 \\
\Delta & =\lambda_{h} \lambda_{f} \lambda_{b}+\lambda_{h} \lambda_{f}+\lambda_{h} \lambda_{b}+\lambda_{f} \lambda_{b} .
\end{aligned}
$$

\section{Proposition 3: FX Order Flow}

The international bond fund is the liquidity provider in the FX market. It does not experience any belief changes. Order flow in the FX market, $O F^{E}$, therefore arises only from the market orders of the international equity fund. Hence,

$$
O F^{E}=k\left[\left(\mu_{e}^{F}-\mu_{e}^{H}\right)\right]
$$

\section{Proposition 4: Reduced Form Structure}

The above system of equations (from proposition 1) can be rewritten as

$$
\left[\begin{array}{ccc}
\left(1+\lambda_{h}\right) \lambda_{f} & -\lambda_{f} & -\lambda_{f} \\
-\lambda_{h} & \left(1+\lambda_{f}\right) \lambda_{h} & \lambda_{h} \\
-1 & 1 & \left(1+\lambda_{b}\right)
\end{array}\right]\left[\begin{array}{c}
R^{H} \\
R^{F} \\
R^{E}
\end{array}\right]=\frac{1}{1+r}\left[\begin{array}{c}
\left(\mu_{e}^{H}-\mu_{e}^{F}\right) \lambda_{f}+\mu_{h}^{H} \lambda_{h} \lambda_{f} \\
\left(\mu_{e}^{F}-\mu_{e}^{H}\right) \lambda_{h}+\mu_{f}^{F} \lambda_{f} \lambda_{h} \\
\mu_{e}^{F}-\mu_{e}^{H}
\end{array}\right] .
$$


Adding the first two equations yields

$$
\left[\begin{array}{ccc}
\left(1+\lambda_{h}\right) \lambda_{f}-\lambda_{h} & \left(1+\lambda_{f}\right) \lambda_{h}-\lambda_{f} & \lambda_{h}-\lambda_{f} \\
-1 & 1 & \left(1+\lambda_{b}\right)
\end{array}\right]\left[\begin{array}{c}
R^{H} \\
R^{F} \\
R^{E}
\end{array}\right]=\frac{1}{1+r}\left[\begin{array}{c}
\left(\mu_{e}^{H}-\mu_{e}^{F}\right)\left(\lambda_{f}-\lambda_{h}\right)+\left(\mu_{h}^{H}+\mu_{f}^{F}\right) \lambda_{h} \lambda_{f} \\
\mu_{e}^{F}-\mu_{e}^{H}
\end{array}\right]
$$

and adding $\left(\lambda_{f}-\lambda_{h}\right)$ times the last equation gives

$$
\left[\begin{array}{ccc}
\lambda_{h} \lambda_{f} & \lambda_{f} \lambda_{h} & \left(\lambda_{f}-\lambda_{h}\right) \lambda_{b} \\
-1 & 1 & \left(1+\lambda_{b}\right)
\end{array}\right]\left[\begin{array}{c}
R^{H} \\
R^{F} \\
R^{E}
\end{array}\right]=\frac{1}{1+r}\left[\begin{array}{c}
\left(\mu_{h}^{H}+\mu_{f}^{F}\right) \lambda_{h} \lambda_{f} \\
\mu_{e}^{F}-\mu_{e}^{H}
\end{array}\right]
$$

Finally, dividing the first equation by $\lambda_{h} \lambda_{f}$, we obtain

$$
\left[\begin{array}{ccc}
1 & 1 & \frac{\left(\lambda_{f}-\lambda_{h}\right) \lambda_{b}}{\lambda_{h} \lambda_{f}} \\
1 & -1 & -\left(1+\lambda_{b}\right)
\end{array}\right]\left[\begin{array}{c}
R^{H} \\
R^{F} \\
R^{E}
\end{array}\right]=\frac{1}{1+r}\left[\begin{array}{c}
\mu_{h}^{H}+\mu_{f}^{F} \\
\mu_{e}^{H}-\mu_{e}^{F}
\end{array}\right]
$$

The order flow definitions allow us to rewrite

$$
\begin{aligned}
& O F^{H}+O F^{F}=k\left[\mu_{h}^{H}+\mu_{f}^{F}\right] \\
& O F^{H}-O F^{F}=k\left[\left(\mu_{h}^{H}-\mu_{f}^{F}\right)+2\left(\mu_{e}^{H}-\mu_{e}^{F}\right)\right] .
\end{aligned}
$$

Note that the exchange rate return can be expressed as

$$
R^{E}=\frac{-\lambda_{f} \lambda_{h}}{(1+r) \Delta}\left(\mu_{e}^{H}-\mu_{e}^{F}\right)+\frac{\lambda_{h} \lambda_{f}}{(1+r) \Delta}\left(\mu_{h}^{H}-\mu_{f}^{F}\right)
$$

or

$$
\begin{aligned}
\frac{1}{\rho_{b}(1+r) \sigma_{E}^{2}} R^{E} & =-k\left(\mu_{e}^{H}-\mu_{e}^{F}\right)+k\left(\mu_{h}^{H}-\mu_{f}^{F}\right) \\
& =-3 k\left(\mu_{e}^{H}-\mu_{e}^{F}\right)+\left(O F^{H}-O F^{F}\right) \\
& =3 O F^{E}+\left(O F^{H}-O F^{F}\right)
\end{aligned}
$$

or

$$
\mu_{e}^{H}-\mu_{e}^{F}=\frac{1}{3 k}\left(O F^{H}-O F^{F}\right)-\frac{1}{3 k(1+r) \rho_{b} \sigma_{E}^{2}} R^{E} .
$$

Substitution then implies

$$
\left[\begin{array}{ccc}
1 & 1 & \lambda_{e} \frac{\left(\lambda_{f}-\lambda_{h}\right)}{\lambda_{h} \lambda_{f}} \\
1 & -1 & -\left(1+\lambda_{b}\right)
\end{array}\right]\left[\begin{array}{c}
R^{H} \\
R^{F} \\
R^{E}
\end{array}\right]=\left[\begin{array}{c}
\frac{1}{k(1+r)}\left(O F^{H}+O F^{F}\right) \\
\frac{1}{3 k(1+r)}\left(O F^{H}-O F^{F}\right)-\frac{1}{3 k \rho_{b}(1+r)^{2} \sigma_{E}^{2}} R^{E}
\end{array}\right]
$$

Adding the two equations implies the following expression for home returns

$$
R^{H}=\frac{1}{3}\left[\left(1+\lambda_{b}\right)+\lambda_{b} \frac{\left(\lambda_{h}-2 \lambda_{f}\right)}{\lambda_{h} \lambda_{f}}\right] R^{E}+\frac{1}{3 k(1+r)}\left(2 O F^{H}+O F^{F}\right)
$$


and subtracting gives

$$
R^{F}=\frac{1}{3}\left[-\left(1+\lambda_{b}\right)+\lambda_{b} \frac{\left(2 \lambda_{h}-\lambda_{f}\right)}{\lambda_{h} \lambda_{f}}\right] R^{E}+\frac{1}{3 k(1+r)}\left(O F^{H}+2 O F^{F}\right)
$$

where we used

$$
\begin{aligned}
\left(1+\lambda_{b}\right)-\frac{1}{3 k \rho_{b}(1+r)^{2} \sigma_{E}^{2}} & =\left(1+\lambda_{b}\right)-\frac{1}{3} \frac{\Delta}{\lambda_{h} \lambda_{f}} \\
& =\left(1+\lambda_{b}\right)-\frac{1}{3}\left\{\left(1+\lambda_{e}\right)+\lambda_{e} \frac{\left(\lambda_{h}+\lambda_{f}\right)}{\lambda_{h} \lambda_{f}}\right\} \\
& =\frac{2}{3}\left(1+\lambda_{b}\right)-\frac{1}{3} \lambda_{e} \frac{\left(\lambda_{h}+\lambda_{f}\right)}{\lambda_{h} \lambda_{f}} .
\end{aligned}
$$




\section{Table 1: Investment Opportunities}

Represented are the investment opportunities for the four funds $i=e, b, h, f$ in the four markets (Yes/No) and the notation for their respective belief innovation in the equity market.

\begin{tabular}{|c|c|c|c|c|c|c|c|c|}
\hline \multirow[t]{4}{*}{ Market } & \multicolumn{8}{|c|}{ Fund Type } \\
\hline & \multicolumn{4}{|c|}{ International Funds } & \multicolumn{4}{|c|}{ Domestic Funds } \\
\hline & \multicolumn{2}{|c|}{ Equity $(e)$} & \multicolumn{2}{|c|}{ Bonds $(b)$} & \multicolumn{2}{|c|}{ Home $(h)$} & \multicolumn{2}{|c|}{ Foreign $(f)$} \\
\hline & Invests? & Innov. & Invests? & Innov. & Invests? & Innov. & Invests? & Innov. \\
\hline \multicolumn{9}{|l|}{ Equity Markets } \\
\hline Home country & Yes & $\mu_{e}^{H}$ & No & - & Yes & $\mu_{h}^{H}$ & No & - \\
\hline Foreign country & Yes & $\mu_{e}^{F}$ & No & - & No & - & Yes & $\mu_{f}^{F}$ \\
\hline \multicolumn{9}{|l|}{ Bond Markets } \\
\hline Foreign country & No & - & Yes & - & No & - & Yes & - \\
\hline Home country & No & - & Yes & - & Yes & - & No & - \\
\hline
\end{tabular}




\section{Table 2: Summary Statistics}

For five year period 01/1999 to $12 / 2003$ we report for the U.S. $(H)$ and French $(F)$ equity market, as well as dollar/euro foreign exchange market $(E)$ the mean, standard deviation (S.D.), and first-order autocorrelation $(\mathrm{AR}(1))$ of the daily stock market returns, $R^{H}(\mathrm{~S} \& \mathrm{P} 100)$ and $R^{F}$ (CAC40), the daily dollar-euro exchange rate return $\left(R^{E}\right)$, the raw daily order flows $(R O F)$, daily trade volume $(V O L)$, and the normalized daily order flow $(O F)$ defined as the ratio of raw order flow and volume. The daily exchange rate order flow is available only for 12 months from 01/1999 to 12/1999.

\begin{tabular}{|c|c|c|c|c|}
\hline & & Mean & S.D. & $\operatorname{AR}(1)$ \\
\hline \multicolumn{5}{|c|}{ Daily Returns } \\
\hline$R^{H}$ & $\%$ & -0.007 & 1.40 & -0.03 \\
\hline$R^{F}$ & $\%$ & -0.008 & 1.66 & 0.002 \\
\hline$R^{E}$ & $\%$ & 0.005 & 0.67 & -0.07 \\
\hline \multicolumn{5}{|c|}{ Raw order flow } \\
\hline$R O F^{H}$ & $\$$ millions & 1412 & 1075 & 0.16 \\
\hline$R O F^{F}$ & $€$ millions & 37 & 344 & 0.17 \\
\hline$R O F^{E}$ & $€$ millions & 519 & 1103 & 0.26 \\
\hline \multicolumn{5}{|c|}{ Daily Volume } \\
\hline$V O L^{H}$ & $\$$ millions & 23206 & 7591 & 0.77 \\
\hline$V O L^{F}$ & $€$ millions & 3153 & 1101 & 0.51 \\
\hline$V O L^{E}$ & $€$ millions & 37217 & 11527 & 0.45 \\
\hline \multicolumn{5}{|c|}{ Daily order flow } \\
\hline$O F^{H}$ & & 0.06 & 0.05 & 0.15 \\
\hline$O F^{F}$ & & 0.01 & 0.1 & 0.18 \\
\hline$O F^{E}$ & & 0.01 & 0.03 & 0.23 \\
\hline
\end{tabular}


Table 3: Reduced Form Estimates

U.S. and French stock returns, $R^{H}$ (S\&P100) and $R^{F}$ (CAC40), respectively, are each regressed on the daily dollar-euro exchange rate return $R^{E}$ as well as daily U.S. $\left(O F^{H}\right)$ and French $\left(O F^{F}\right)$ equity order flow. The equations are estimated using ordinary least squares for the whole sample (OLS, 01/199912/2003), ordinary least squares for 1999 only (OLS, 01/1999-12/1999), and two stage least squares for 1999 using foreign exchange order flow as an instrument for exchange rate returns (2SLS, 01/199912/1999). We also report a seemingly unrelated regressions (SUR (Restricted), 01/1999-12/2003) which imposes the exact parameter restrictions. T-tests in parentheses use White's robust standard errors.

Equation 1: U.S. Equity Returns

$$
R^{H}=\frac{1}{3}\left[\left(1+\lambda_{b}\right)+\lambda_{b} \frac{\left(\lambda_{h}-2 \lambda_{f}\right)}{\lambda_{h} \lambda_{f}}\right] R^{E}+\frac{1}{3 k(1+r)}\left(2 O F^{H}+O F^{F}\right)
$$

OLS SUR (Restricted) OLS 2SLS

\begin{tabular}{|c|c|c|c|c|c|c|c|c|}
\hline Period & \multicolumn{2}{|c|}{ 01/1999-12/2003 } & \multicolumn{2}{|c|}{ 01/1999-12/2003 } & \multicolumn{2}{|c|}{ 01/1999-12/1999 } & \multicolumn{2}{|c|}{ 01/1999-12/1999 } \\
\hline$R^{E}$ & -0.22 & $(4.61)$ & -0.27 & (6.04) & -0.22 & $(2.71)$ & -0.23 & (1.71) \\
\hline$O F^{H}$ & 21.50 & $(27.58)$ & 11.58 & $(40.63)$ & 16.81 & $(17.75)$ & 16.77 & $(15.95)$ \\
\hline$O F^{F}$ & 2.49 & $(9.12)$ & 5.79 & $(40.63)$ & 2.47 & $(4.21)$ & 2.45 & $(4.02)$ \\
\hline$R^{2}$ & $58.9 \%$ & & $46.5 \%$ & & $63.0 \%$ & & $62.8 \%$ & \\
\hline $\mathrm{Q}(5)$ & 1.66 & & 1.66 & & 4.30 & & 4.27 & \\
\hline Hausm. Test & & & & & \multicolumn{4}{|c|}{$\chi^{2}(4)=0.05$} \\
\hline Chow Test & \multicolumn{8}{|c|}{$\chi^{2}(3)=4.39$} \\
\hline
\end{tabular}

Equation 2: French Equity Returns

$$
R^{F}=\frac{1}{3}\left[-\left(1+\lambda_{b}\right)+\lambda_{b} \frac{\left(2 \lambda_{h}-\lambda_{f}\right)}{\lambda_{h} \lambda_{f}}\right] R^{E}+\frac{1}{3 k(1+r)}\left(O F^{H}+2 O F^{F}\right)
$$

\begin{tabular}{|c|c|c|c|c|c|c|c|c|}
\hline Period & \multicolumn{2}{|c|}{ 01/1999-12/2003 } & \multicolumn{2}{|c|}{ 01/1999-12/2003 } & \multicolumn{2}{|c|}{ 01/1999-12/1999 } & \multicolumn{2}{|c|}{ 01/1999-12/1999 } \\
\hline$R^{E}$ & -0.17 & $(2.89)$ & -0.13 & $(2.34)$ & -0.20 & $(2.12)$ & -0.38 & $(2.33)$ \\
\hline$O F^{H}$ & 7.32 & $(8.39)$ & 5.79 & (40.63) & 3.86 & $(3.34)$ & 3.08 & $(2.48)$ \\
\hline$O F^{F}$ & 9.19 & (16.69) & 11.58 & (40.63) & 6.86 & $(7.58)$ & 6.61 & $(7.28)$ \\
\hline$R^{2}$ & $40.1 \%$ & & $38.2 \%$ & & $46.4 \%$ & & $44.5 \%$ & \\
\hline $\mathrm{Q}(5)$ & 3.58 & & 3.58 & & 5.81 & & 4.64 & \\
\hline Hausm. Test & & & & & \multicolumn{4}{|c|}{$\chi^{2}(2)=3.79$} \\
\hline Chow Test & & & & 2.62 & & & & \\
\hline
\end{tabular}

OLS SUR (Restricted) OLS 2SLS 


\section{Table 4: Uncovered Equity Returns Parity}

In equation 3, the deviation between U.S. and French equity returns, expressed in U.S. dollars, $R^{H}-$ $R^{F}-R^{E}$ is regressed on daily dollar-euro exchange rate returns $R^{E}$ as well as daily U.S. $\left(O F^{H}\right)$ and French $\left(O F^{F}\right)$ equity order flow. The equation is estimated using ordinary least squares for the whole sample (01/1999-12/2003). In equation 4 , the same dependant variable is regressed on daily dollar-euro order flow $O F^{E}$ and again on U.S. $\left(O F^{H}\right)$ and French $\left(O F^{F}\right)$ equity order flow for the first year of the sample (01/1999-12/1999). T-tests are in parentheses. They are calculated using Newey West robust standard errors, which also correct for autocorrelation.

Equation 3: Exchange Rate Return as Independent Variable

$$
R^{H}-R^{F}-R^{E}=\frac{1}{3} \gamma R^{E}+\frac{1}{3 k(1+r)}\left[O F^{H}-O F^{F}\right]
$$

Equation 4: Exchange Rate Order Flows as Independent Variable

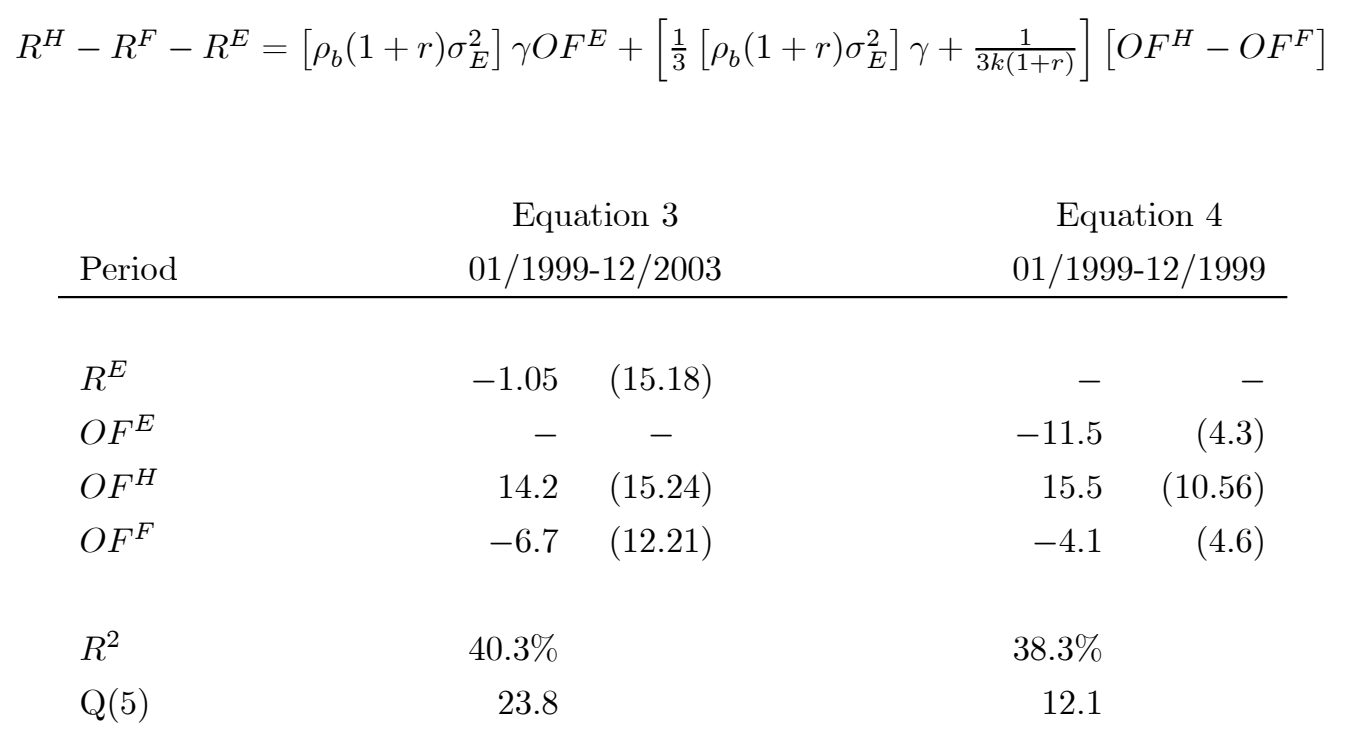




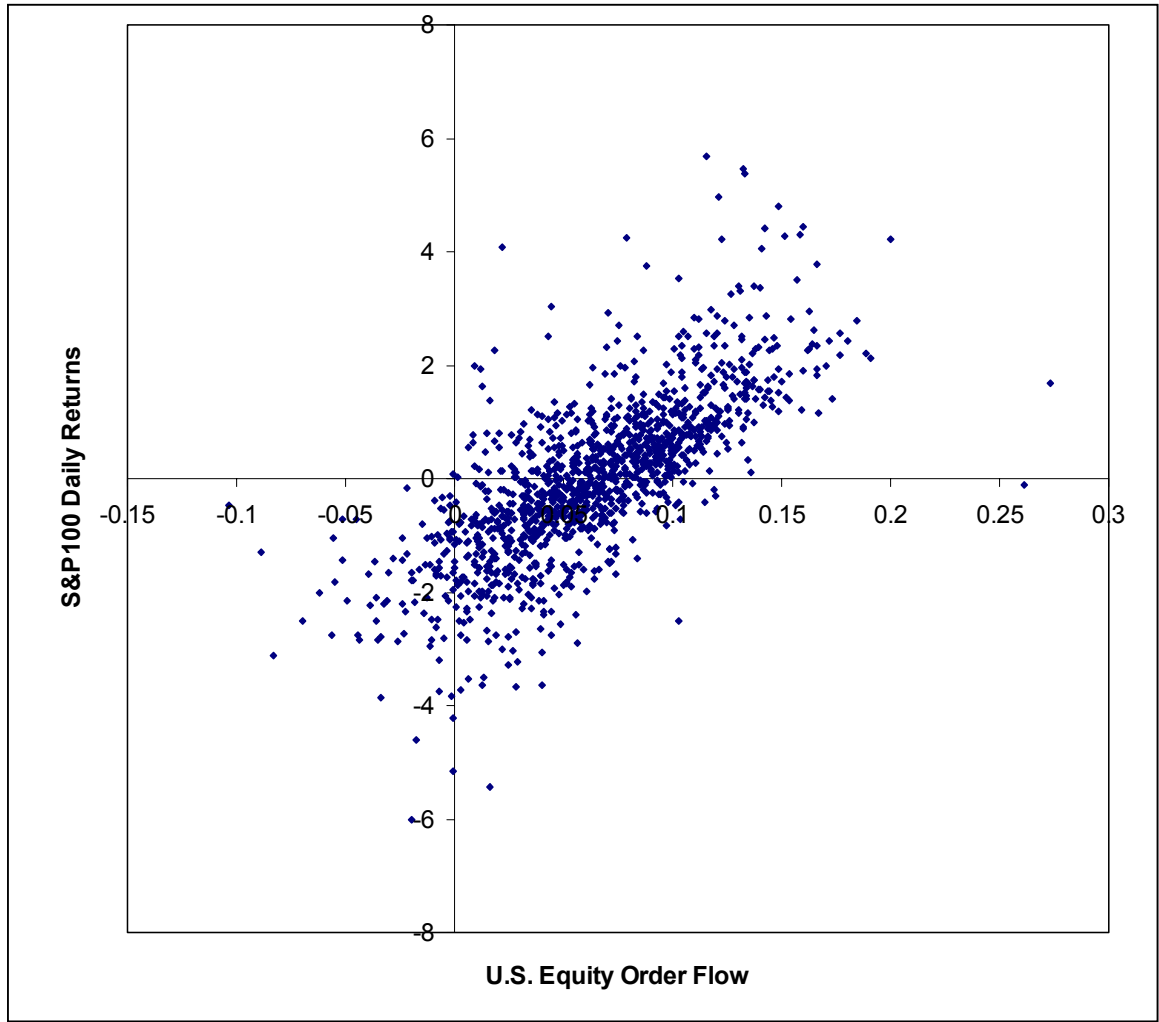

Figure 2: Plotted are daily returns in the S\&P100 index against normalized daily order flow into the U.S. equity market for the five year period 1999 to 2003. 


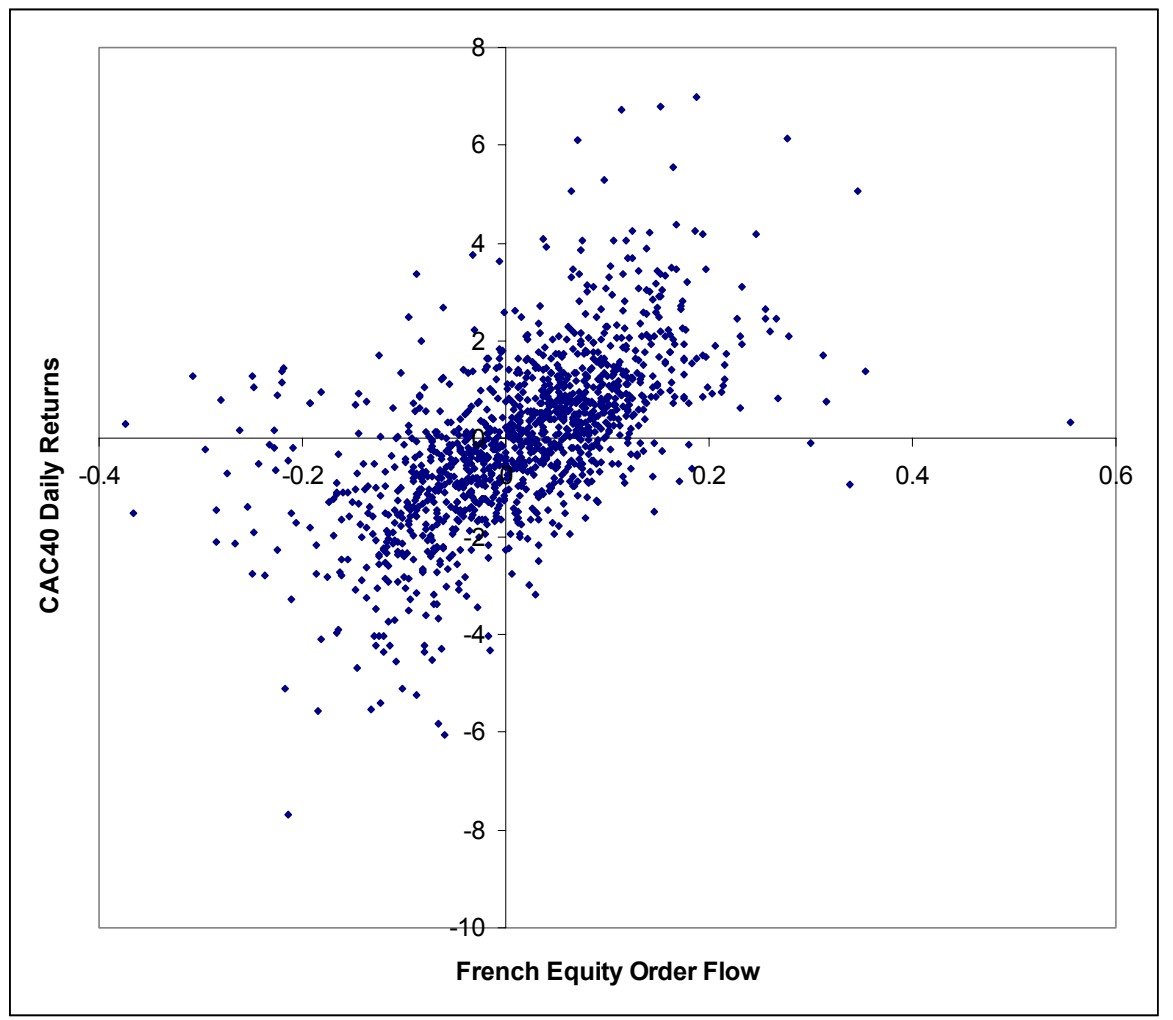

Figure 3: Plotted are daily returns in the CAC40 index against normalized daily order flow into the French equity market for the five year period 1999 to 2003. 


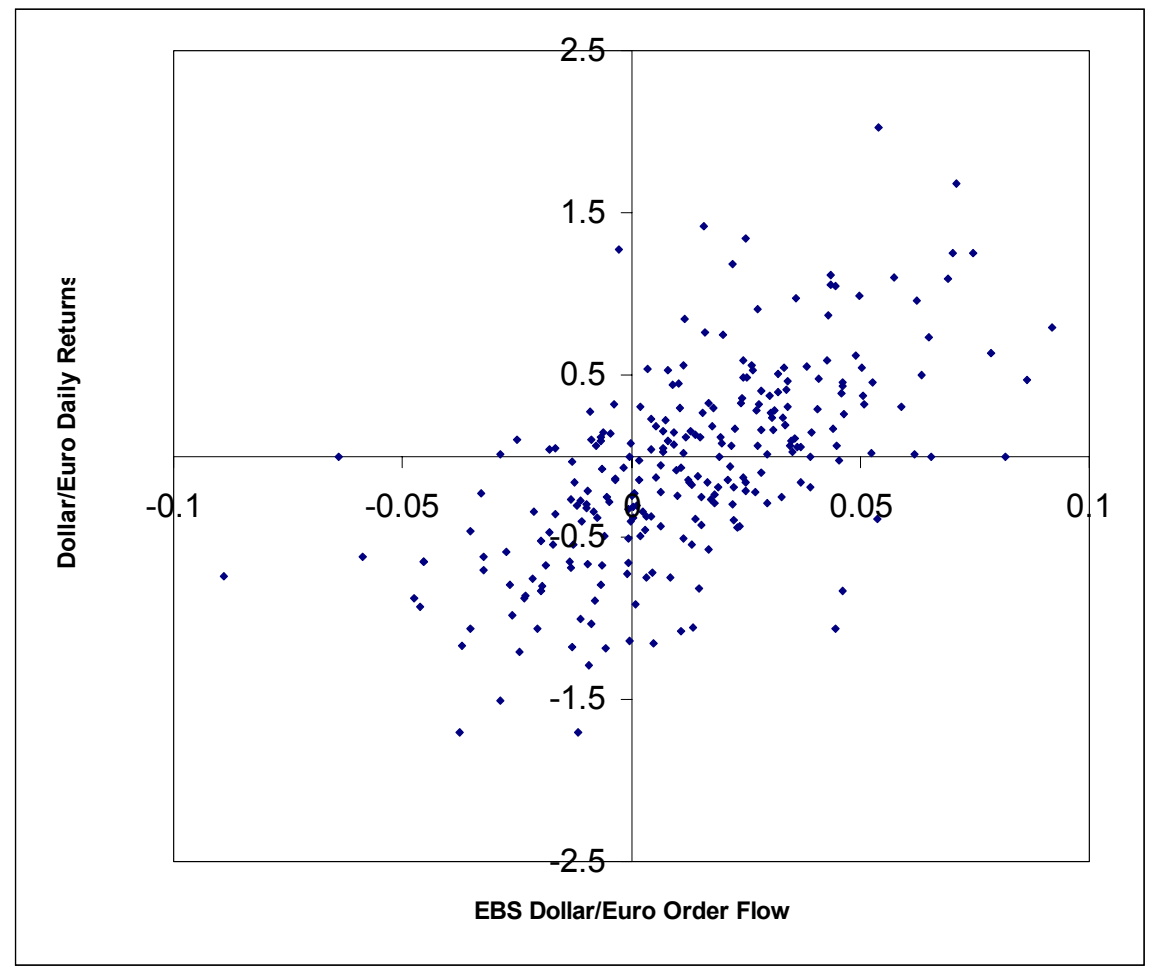

Figure 4: Plotted are daily returns in the Dollar/Euro exchange rate against normalized daily order flow in the EBS trading system for the year 1999. 